\title{
BMJ Global Health What's needed to improve safety and quality of abortion care: reflections from WHO/HRP Multi-Country Study on Abortion across the sub-Saharan Africa and Latin America and Caribbean regions
}

\author{
Hedieh Mehrtash, Caron Rahn Kim, Bela Ganatra, Özge Tuncalp
}

To cite: Mehrtash H, Kim CR, Ganatra B, et al. What's needed to improve safety and quality of abortion care: reflections from WHO/HRP Multi-Country Study on Abortion across the sub-Saharan Africa and Latin America and Caribbean regions. BMJ Global Health 2021;6:e007226. doi:10.1136/ bmjgh-2021-007226

Received 18 August 2021 Accepted 19 August 2021
Check for updates

(C) Author(s) (or their employer(s)) 2021. Re-use permitted under CC BY. Published by BMJ.

UNDP/UNFPA/UNICEF/WHO/ World Bank Special Programme of Research, Development and ResearchTraining in Human Reproduction (HRP), Department of Sexual and Reproductive Health and Research, World Health Organization, Geneva, Switzerland

Correspondence to Hedieh Mehrtash; mehrtashh@who.int

\section{INTRODUCTION}

In the advent of safe methods, access to information and trained providers, abortion has become a very safe procedure; however, unsafe abortions continue to persist in many parts of the world. Unsafe abortions account for half of all abortions globally, with the majority occurring in sub-Saharan Africa and Latin America and Caribbean (LAC). ${ }^{1}$ Severe abortion-related complications arise from least safe abortions. ${ }^{1}$ Between 2008 and 2013, it was estimated that approximately $10 \%$ of maternal deaths are attributable to abortion-related causes in sub-Saharan Africa and LAC $^{2}$; however, studies exploring abortion morbidity and mortality including management of these complications have been limited or varied in estimations of the complications limiting comparability as there has been a lack of standard definitions, identification criteria and measurement tools.

\section{WHO/HUMAN REPRODUCTION PROGRAMME (HRP) MULTI-COUNTRY STUDY ON ABORTION}

Since the early 2000s, WHO/HRP has been conducting a series of WHO Multi-Country Studies (MCSs) on maternal and newborn health across multiple countries and health facilities globally. ${ }^{3-5}$ Using the original WHO MCS methodology and network, ${ }^{6}$ the WHO Multi-Country Study on Abortion (MCS-A) ${ }^{7}$ study aimed at measuring the prevalence and management of abortion-related complications across health facilities in LAC and subSaharan Africa. One of the key contributions of this MCS was to use standardised definitions for severity of complications using WHO criteria on near miss and potentially lifethreatening conditions. ${ }^{8}$ Given the growing
Summary box

Complications as a result of unsafe abortion are an important and preventable cause of maternal mortality and morbidity.

- Based on indicators present at the time of facility admission, abortion-related complications were classified into five hierarchical and mutually exclusive categories based on severity: (1) severe materna outcomes consists of mortality and near miss (3) potentially life-threatening complications, (4) moderate complications and (5) mild complications.

- Across sub-Saharan Africa and Latin America and Caribbean regions, our findings illustrate that the majority of complications were moderate and mild complications, and marginally more severe complications in sub-Saharan Africa.

- Women's experiences of abortion care across both regions underlined the need for effective communication and emotional support including reducing anxiety and stress during examinations.

- A multi-pronged approach including self-care, clinical care, task sharing, human rights and enabling legal environment is needed to deliver high-quality abortion and postabortion care including access to contraceptives.

interest around women's experiences of care, the study also adapted WHO's quality of care framework on maternal and newborn health to explore women's self-reported experiences of postabortion care (including contraception method of choice) as pertained to respect and dignity, effective communication and support. ${ }^{9}$

Data on women seeking care for abortionrelated complications, including ectopic and molar pregnancies at the time of facility admission were abstracted from medical records. Abortion-related complications were 


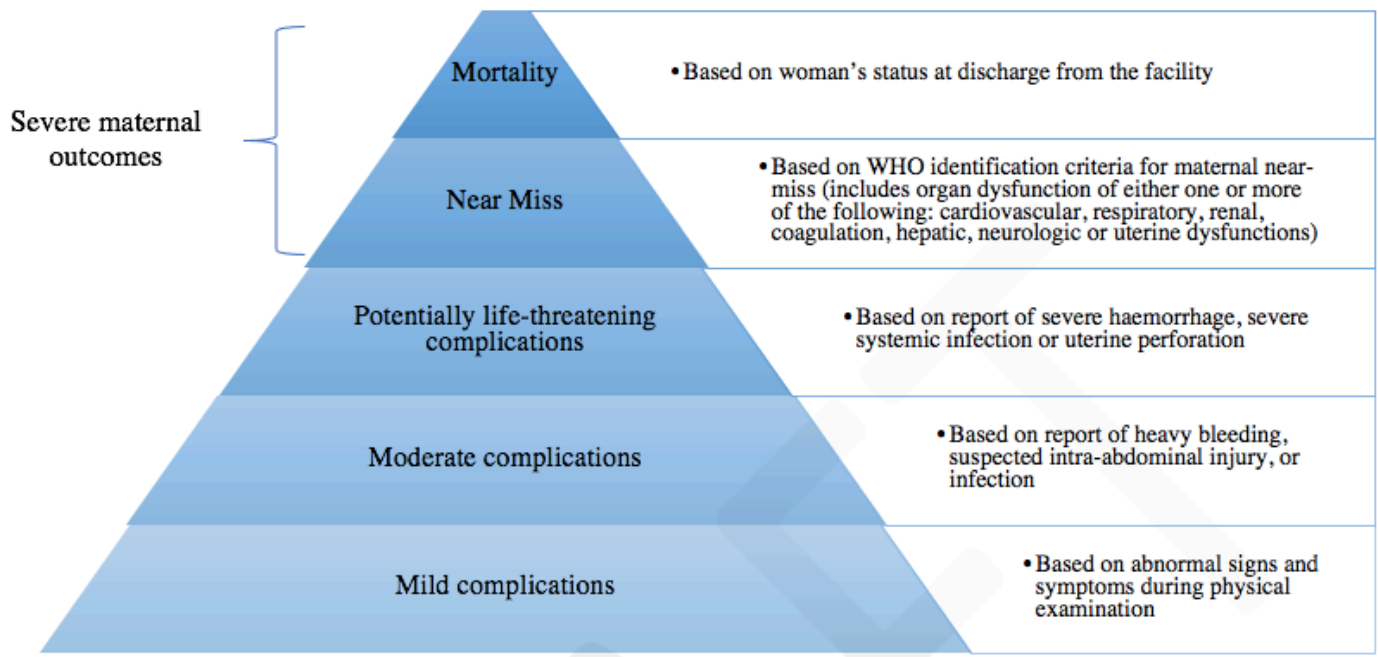

Figure 1 WHO/Human Reproduction Programme Multi-Country Study on Abortion severity of abortion-related complications.

classified into five hierarchical and mutually exclusive categories based on severity ${ }^{1}$ : deaths, ${ }^{2}$ near miss, ${ }^{3}$ potentially life-threatening complications, ${ }^{4}$ moderate complications and ${ }^{5}$ mild complications (figure 1). In addition to the original methodology, an Audio ComputerAssisted Self-Interviewing (ACASI), a system well-suited for collecting data confidentially on sensitive topics such as abortion were included to document women's experiences of care. ${ }^{1011}$

As a result, the WHO MCS-A was conducted in 17 countries across sub-Saharan Africa and the LAC regions. ${ }^{12} 13$ In Africa, the study was conducted in 211 facilities across Benin, Burkina Faso, Chad, Democratic Republic of Congo, Ghana, Kenya, Malawi, Mozambique, Niger, Nigeria and Uganda. In LAC, the study was conducted in 70 facilities across Argentina, Brazil, Bolivia, Dominican Republic, El Salvador and Peru.

\section{SEVERITY AND MANAGEMENT OF ABORTION-RELATED COMPLICATIONS}

Across both regions, our findings illustrate that the majority of complications were moderate and mild complications with marginally more severe complications identified in sub-Saharan Africa (figure 2). This is in line with abortion safety estimates where sub-Saharan Africa is estimated to have the highest proportion of abortions that are conducted under least safe conditions leading to severe complications. ${ }^{1}$

In sub-Saharan Africa and LAC, women who were single, presenting $\geq 13$ weeks of gestational age and where expulsion of products of conception occurred prior to arrival to facility were more likely to experience severe abortion-related complications. Abortion remains a stigmatised issue limiting equitable access to care for women based on their socioeconomic characteristics, such as marital status, contributing to severe complications. In

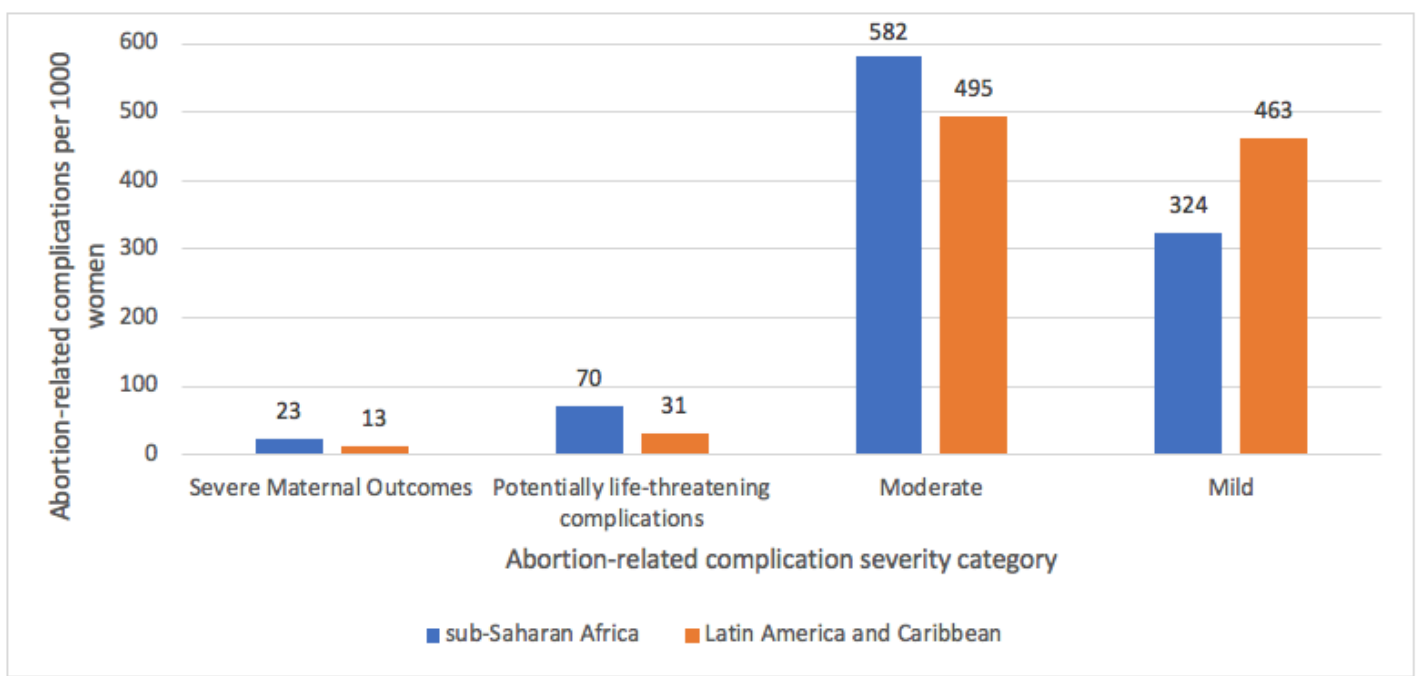

Figure 2 Abortion-related complications across sub-Saharan Africa and Latin America and Caribbean regions. 
restrictive settings, not only are services for safe abortion limited but vague abortion laws and policies, lack of access to accurate information, medication, equipment and limitations on the provider types who can provide abortion care, are contributing factors that may lead women to delay seeking care for complications if they do occur. $^{14}$

In terms of management, manual vacuum aspiration and misoprostol were most commonly used to manage abortion-related complications. In both regions, the use of dilation and curettage was still used. Another striking finding from our study is the ample use of antibiotics to manage abortion-related complications highlighting the need to regulate and promote appropriate use of antibiotics and combat antibiotic resistance. ${ }^{15}$ Global efforts must focus on transitioning to evidence-based methods both for provision of abortion and management of complications.

Via ACASI, both in in sub-Saharan Africa and LAC, of those who responded that method was used to induce their abortion, one in twowomen reported using misoprostol. Used correctly, misoprostol (used in combination with mifepristone) or by itself is a safe and effective method recommended in WHO guidelines. ${ }^{16-18}$ Provision of safe abortion care requires effective adoption and implementation of WHO recommendations. Strengthening these efforts will be essential to those involved in quality abortion care, in particular the women, providers and policy makers.

\section{WOMEN'S EXPERIENCES OF POSTABORTION CARE}

While there is room for improvement needed on the provision of postabortion care and management, women's experiences of care across both regions underlined the need for emotional support including reducing anxiety and stress during examinations, and effective communication such as having questions answered during the time of care. These findings warrant further research around improving quality of care, especially focusing on experience of care during this time. To explore some of these issues in the study database, the study team is currently working on a set of secondary analyses to be published in 2021. While more work is needed on understanding and improving women's experiences of care, it will be pertinent to tackle stigma surrounding abortion globally. Evidence on various approaches to reduce abortion stigma have clearly shown that it hinders access at all levels of level care ${ }^{19}$ Future programmes must consider how stigma can affect delays to care, access to accurate information, and available social and financial support, all of which have economic and health implications. It will be important to use new approaches to reach women that are not reaching facility-level care. WHO is currently exploring network-based methods ${ }^{20}$ to better understand how women's social networks can deter or refer her to reach safe abortion care services.

\section{CONCLUSION}

Unsafe abortion is a serious area of concern in subSaharan African and LAC countries resulting in significant morbidity for women and burden on health systems. It will be important to use a standardised approach to quantify abortion-related complications and incorporate women's experiences of abortion care to improve postabortion care services. It is critical to decrease the risk of severe abortion morbidity by using innovative outreach efforts to provide women with appropriate information and support to reduce delays in care-seeking. Moving forward it is important to incorporate a multi-pronged approach including self-care, clinical care, task sharing, human rights and enabling legal environment to deliver high-quality abortion and postabortion care including access to contraceptives.

Twitter Hedieh Mehrtash @hediehmm, Bela Ganatra @bganatra and Özge Tuncalp @otuncalp

Acknowledgements The WHO Multi-Country Survey on Abortion-related morbidity (MCS-A) is a research project implemented by the WHO across a network of health facilities in Latin America and Caribbean, and sub-Saharan Africa. We sincerely thank the women who participated in this study. WHO is grateful to the extensive network of institutions and individuals who contributed to the project design and implementation, including researchers, study coordinators, data collectors, data clerks and other partners including the staff from the Ministries of Health and WHO offices.

Contributors CRK, OT, BG conceptualised the study and codeveloped the study protocol with the research group. HM and CRK developed outline of commentary. HM wrote the first draft of the commentary. CRK, OT, BG contributed to messaging and commented on previous versions of the commentary. All members authors approved the final manuscript.

Funding This research was funded by the UNDP/UNFPA/UNICEF/WHO/World Bank Special Programme of Research, Development and Research Training in Human Reproduction (HRP), Department of Reproductive Health and Research, WHO.

Disclaimer The contents of this article are the sole responsibility of the authors and do not necessarily reflect the views of WHO, or their individual institutions.

\section{Competing interests None declared.}

\section{Patient consent for publication Not required.}

Ethics approval This study was approved by the WHO Ethical Review Committee (protocol: 0002699) and the WHO Human Reproduction Programme (HRP) Review Panel on Research Projects. This study was also approved by in-country ethical committees in sub-Saharan Africa study sites: Benin (le comité national d'éthique pour la recherche en santé); Burkina Faso (le ministère de la recherché scientifique et de l'innovation); Chad (ministère de l'enseignement supérieur et de la recherche scientifique); Democratic Republic of Congo (Ecole de santé publique comité d'éthique); Ghana (Ethical Review Committee of the Ghana Health Service; Ethical and Protocol Review Committee of the College of Health Sciences, University of Ghana); Kenya (University of Nairobi Ethics and Research Committee); Malawi (College of Medicine Research Ethics Committee (COMREC)); Mozambique (Comité Nacional de Bioetica para e saude, Ministerio de Saude); Nigeria (Federal Capital Territory Health Research Ethics Committee; Research Ethical Review Committee, Oyo State; and State Health Research Ethics Committee of Ondo State) and Uganda (Mulago Hospital Research Committee; Uganda National Council for Science and Technology). This study was also approved by country ethical committees in Latin America and Caribbean study sites: Argentina (Comité de Ética en Investigación, Gobierno de la Ciudad de Buenos Aires; Comités de Docencia e Investigación y Comités de Ética de Hospital de General de Agudos Dr T Álvarez, Hospital General de Agudos Ramos Mejía, Hospital General de Agudos Cosme Argerich, Hospital General de Agudos Donación Santojanni, Hospital Materno Infantil Dr. Ramón Sardá, Comité de Investigación y Docencia Hospital Escuela Eva Perón; Comité de Ética en Investigación, Gobierno de la Ciudad de Santa Fe; Comité de Investigación y Docencia de la Secretaría de Salud de Rosario; Comité de Docencia del Hospital Dra. Olga Stucky, Comité de Docencia del Hospital Provincial del Centenario, Comité de Ética de la Investigación del Hospital Provincial de Rosario, Comité de Docencia e 
Investigación del Hospital Roque Saénz Peña, Comité de Ética en Investigación del Hospital J. M. Cullen, Comité de Docencia e Investigación del Hospital J. B. Iturraspe). Bolivia (Comité Nacional de Bioética; Comité de Revisión Ética (PAHO-ERC)); Brazil (Comissao Nacional de Ética em Pesquisa (CONEP), Fundação de Ensino e Pesquisa em Ciências da Saúde/FEPECS/SES/DF, Secratario de Estado de Saude de Distrito Federal; UNICAMP; Centro Universitario Do Maranhao); Dominican Republic (Servicio Nacional de Salud; Hospital Ricardo Limardo; Hospital de la Mujer Dominicana, Hospital Docente Maternidad de Nuestra Señora de Altagracia, Hospital Marcelino Vélez, General Vinicio Calventi, Hospital Materno Infantil San Lorenzo de los Mina, Hospital Reynaldo Almaza); El Salvador (Comité de Ética en Investigación Clínica, Ministerio de Salud); Peru (Comité Institucional de Ética en Investigación, Ministerio de Salud, Peru; Instituto Nacional Materno Perinatal, Ministerio de Salud; ESSALUD; Gobierno Regional Piura; Hospital Nacional Docente Madre Niño San Bartolomé, Hospital Nacional Sergio E. Bernales, Hospital San Juan de Lurigancho, Hospital María Auxiliadora, Comité de Evaluación Metodológico y Estadística en la Investigación y Comité de Ética en Investigación Hospital Nacional Materno Perinatal, Comité de Capacitación, Investigación y Docencia Hospital Nacional Eduardo Rebagliati Martins, Comité de Capacitación, Investigación y Docencia Hospital Nacional Guillermo Almera Irigoyen, Comité de Ética para la Investigación Hospital Uldarico Rocca Fernandez, Comité de Investigación Hospital de la Amistad Perú Corea Santa Rosa II, Comité de Investigación Hospital III José Cayetano Heredia).

Provenance and peer review Not commissioned; internally peer reviewed.

Data availability statement Data available upon request. The data used for this analysis might be made available upon reasonable request, in accordance with the WHO/HRP MCS-A Research Group data sharing policy and WHO Policy of Data Use and Data Sharing. For further information, contact srhmph@who.int and srhpua@ who.int.

Open access This is an open access article distributed in accordance with the Creative Commons Attribution 4.0 Unported (CC BY 4.0) license, which permits others to copy, redistribute, remix, transform and build upon this work for any purpose, provided the original work is properly cited, a link to the licence is given, and indication of whether changes were made. See: https://creativecommons.org/ licenses/by/4.0/.

\section{REFERENCES}

1 Ganatra B, Gerdts C, Rossier C, et al. Global, regional, and subregional classification of abortions by safety, 2010-14: estimates from a Bayesian hierarchical model. The Lancet 2017;390:2372-81.

2 Say L, Chou D, Gemmill A, et al. Global causes of maternal death: a who systematic analysis. Lancet Glob Health 2014;2:e323-33.

3 Souza JP, Cecatti JG, Haddad SM, et al. The WHO maternal nearmiss approach and the maternal severity index model (MSI): tools for assessing the management of severe maternal morbidity. PLoS One 2012;7:e44129.

4 Souza JP, Gülmezoglu AM, Vogel J, et al. Moving beyond essential interventions for reduction of maternal mortality (the who multicountry survey on maternal and newborn health): a crosssectional study. Lancet 2013;381:1747-55.

5 Souza JP, on behalf of the WHO Multicountry Survey on Maternal and Newborn Health Research Network. The world Health organization multicountry survey on maternal and newborn health project at a glance: the power of collaboration. BJOG: Int J Obstet Gy 2014;121:v-viii.

6 Shah A, Faundes A, Machoki M'Imunya, Machoki M, et al. Methodological considerations in implementing the who global survey for monitoring maternal and perinatal health. Bull World Health Organ 2008;86:126-31.

7 Kim CR, Tunçalp Özge, Ganatra B, et al. Who Multi-Country survey on Abortion-related morbidity and mortality in health facilities: study protocol. BMJ Glob Health 2016;1:e000113.

8 Say L, Souza JP, Pattinson RC, et al. Maternal near miss--towards a standard tool for monitoring quality of maternal health care. Best Pract Res Clin Obstet Gynaecol 2009;23:287-96.

9 Tunçalp Ö, Were WM, MacLennan C, et al. Quality of care for pregnant women and newborns-the who vision. BJOG 2015;122:1045-9.

10 Lessler JT, O'Reilly JM. Mode of interview and reporting of sensitive issues: design and implementation of audio computer-assisted selfinterviewing. NIDA Res Monogr 1997;167:366-82.

11 O'Reilly JM, Hubbard ML, Lessler JT, et al. Audio and video computer-assisted self interviewing: preliminary tests of new technologies for data collection. J Off Stat 1994;10:197-214.

12 Qureshi Z, Mehrtash H, Kouanda S, et al. Understanding abortionrelated complications in health facilities: results from who multicountry survey on abortion (MCS-A) across 11 sub-Saharan African countries. BMJ Glob Health 2021;6:e003702.

13 Romero M, Gomez Ponce de Leon R, Baccaro LF, et al. Abortionrelated morbidity in six Latin American and Caribbean countries: findings of the WHO/HRP multi-country survey on abortion (MCS-A). BMJ Glob Health 2021;6. doi:10.1136/bmjgh-2021-005618. [Epub ahead of print: 2008 2021]

14 Assifi AR, Berger B, Tunçalp Özge, et al. Women's awareness and knowledge of abortion laws: a systematic review. PLoS One 2016;11:e0152224.

15 WHO antibiotic resistance fact sheet. Available: https://www.who.int/ news-room/fact-sheets/detail/antibiotic-resistance

16 World Health Organization. Clinical practice Handbook for safe abortion. Geneva Switzerland, 2012.

17 World Health Organization. Medical management of abortion. Geneva Switzerland, 2018.

18 World Health Organization. Health worker roles in providing safe abortion care and post-abortion contraception. Geneva, Switzerland, 2015.

19 Moore B, Poss C, Coast E, et al. The economics of abortion and its links with stigma: a secondary analysis from a scoping review on the economics of abortion. PLoS One 2021;16:e0246238.

20 Rossier C, Marchin A, Kim C, et al. Disclosure to social network members among abortion-seeking women in low- and middleincome countries with restrictive access: a systematic review. Reprod Health 2021;18:114. 